Научная статья

УДК 376.1

DOI: $10.18101 / 2307-3330-2021-2-16-20$

\title{
ОПЫТ РАЗВИТИЯ СЕНСОРНЫХ ПРОЩЕССОВ ОБУЧАЮЩИХСЯ В УСЛОВИЯХ КОРРЕКЦИОННОЙ ШКОЛЫ
}

\author{
(C) Будаева Сэсэг Дагбадоржиевна \\ педагог-психолог, \\ Специальная коррекционная общеобразовательная школа-интернат № 2 \\ г. Улан-Удэ \\ Россия, 670047, г. Улан-Удэ, ул. Дальневосточная, 1 \\ seseg1407@mail.ru
}

\begin{abstract}
Аннотация. В статье поднимается вопрос актуальности сенсорного развития детей с интеллектуальной недостаточностью. Отмечено что наглядное чувственное знакомство с предметами и их свойствами составляет основу гармоничного развития ребенка. Многие проблемы сенсорной сферы могут быть преодолены лишь в ходе целенаправленной коррекционно-развивающей работы. Анализируется опыт развития сенсорных процессов школьников с умеренной интеллектуальной недостаточностью в процессе коррекционных занятий на базе школы-интерната. Коррекционно-развивающая программа в количестве 102 часа реализована в 2020/21 учебном году. При оценке сенсорных показателей использованы данные диагностических заданий Н. И. Озерецкого, М. О. Гуревича, наблюдения, беседы. Примеры типичных ситуаций коррекционных занятий и результаты программы свидетельствуют о своеобразии сенсорного развития детей с умеренной интеллектуальной недостаточностью.
\end{abstract}

Ключевые слова: умеренная интеллектуальная недостаточность, сенсорное развитие, сенсорная комната, результаты коррекционной работы, специальная коррекционная общеобразовательная школа-интернат.

\section{Для цитирования}

Будаева С. Д. Опыт развития сенсорных процессов обучающихся в условиях коррекционной школы // Вестник Бурятского государственного университета. Образование. Личность. Общество. 2021. № 2. С. 16-20.

Проблемы сенсорного развития детей с интеллектуальной недостаточностью рассматривались многими педагогами и психологами: И. М. Соловьевым, К. И. Вересотской, М. М. Нудельманом, Е. М. Кудрявцевым и др., в том числе у детей с умеренной интеллектуальной недостаточностью А. Р. Маллером, М. В. Жигоревой и др. [8]. В частности, изучение проблемы А. В. Запорожцем, А. П. Усовой, Н. П. Сакулиной, В. С. Мухиной, Л. А. Венгером показало, что развитие сенсорно-перцептивной сферы обучающихся с ОВ3 содержит в качестве основы усвоение детьми сенсорных эталонов и овладение способами обследования предметов, то есть ребенка нужно научить ощупывать, рассматривать, сравнивать, сопоставлять, соотносить обнаруженные свойства и качества предмета со свойствами и качествами других предметов [6]. Под сенсорными эталонами понимаются выработанные человечеством представления о цвете, форме, величине предметов, их положении в пространстве, высоте звука, длительности 
С. Д. Будаева. Опыт развития сенсорных процессов обучающихся в условиях коррекционной школы

промежутков времени и т. д., используемые в качестве образцов, мерок и внутренних образцов при обследовании объектов и выделении их свойств (А. В. Запорожец) [2].

Сенсорное развитие детей с интеллектуальными нарушениями, в частности с умеренной интеллектуальной недостаточностью, отличается качественным своеобразием. Основная проблема в том, что эталонные представления формируются со значительным опозданием, в связи с чем отмечаются ошибки при назывании признаков, свойств, качеств предметов. Многие дети испытывают затруднения в умении выделять цвет, форму как признак предмета, в восприятии времени, глубины, в пространственной ориентировке, соответственно, решение наглядно-практических задач достигается огромным количеством проб и ошибок [3]. Вышеуказанные особенности развития влияют на характер социализации, формирование учебной, внеучебной деятельности. Однако и при умеренной, и при тяжелой интеллектуальной недостаточности возможно формирование сенсорно-перцептивных процессов (В. И. Лубовский, М. С. Певзнер и др.). У большинства детей сохранено конкретное мышление, эмоционально-волевая сфера на более высоком уровне, чем познавательная, развита потребность в общении, неплохо они выполняют трудовую деятельность [4]. Раннее начало коррекционной работы, подбор специальных методов, приемов и средств обучения, учитывающих особенности психического развития детей с умеренной интеллектуальной недостаточностью, позволяют максимально корригировать дефект и обеспечить профилактику вторичных отклонений [8].

Процесс обучения и воспитания в школах VIII вида носит коррекционную направленность. С целью изучения особенностей сенсорного развития обучающихся с умеренной интеллектуальной недостаточностью в 2020/21 учебном году проведено исследование на базе ГБОУ «Специальная коррекционная общеобразовательная школа-интернат № 2» г. Улан-У дэ. Выборку исследования в количестве 21 человека составили дети в возрасте 11-12 лет, обучение которых ведется по второму варианту АООП образования обучающихся с умственной отсталостью (интеллектуальными нарушениями). Для отслеживания развития сенсорных процессов проведена входная и итоговая диагностика с применением диагностических заданий Н. И. Озерецкого, М. О. Гуревича. Результаты входной диагностики показали, что у $43 \%$ детей низкий уровень сформированности сенсорных эталонов цвета, формы, величины. У $34 \%$ детей - средний уровень и у $23 \%-$ выше среднего уровень сенсорного развития. Затруднения у детей вызывают задания на определение и соотношение цветов, форм геометрических фигур, пространственного расположения, величины предметов, наиболее доступными и привлекательными оказались упражнения на слуховое восприятие. Далее в течение учебного года была реализована коррекционно-развивающая программа, состоящая из следующих разделов: тактильно-двигательное восприятие, восприятие формы, величины, цвета, развитие зрительного восприятия, восприятие особых свойств предметов (развитие осязания, обоняния, вкусовых качеств, барических ощущений), развитие слухового восприятия, восприятие пространства, восприятие времени. Все разделы программы курса занятий взаимосвязаны, по каждому спланировано усложнение заданий. В основе системы занятий лежит комплексный подход, предусматривающий решение на одном занятии разных, но 
однонаправленных задач из нескольких разделов программы, способствующих целостному психическому развитию ребенка (например, формирование представлений о форме предмета, развитие тактильного восприятия, упражнения на пространственную ориентировку в классной комнате, развитие зрительной памяти и т. д.). Еще одной технологией сенсомоторного развития детей в условиях специальной коррекционной школы-интерната является работа в сенсорной комнате, где особым образом организована окружающая среда для коррекции и развития. Занятия в сенсорной комнате позволяют повышать активность всех анализаторных систем, стимулируют у детей зрительные, слуховые, тактильные ощущения, тем самым являясь дополнением к традиционным методам коррекции, для которых характерно небольшое количество и однообразие материала [1]. Повышение интереса, движение, познание, расширение жизненного опыта детей, обогащение чувственного мира детей - все это заложено в оборудовании сенсорной комнаты, значительно повышающем эффективность и результативность образовательных, коррекционных мероприятий [5].

На начальных этапах проведения занятий обнаружено, что часть школьников не понимала инструкцию, даже при повторении и упрощении ее, многие учащиеся допускали ошибки при соотнесении и назывании цвета, формы, величины, пространственной ориентации. Небольшое количество детей имело устойчивые знания о геометрических формах, но в то же время из-за нарушений речи наблюдалось своеобразие в их назывании. Те же самые наблюдения касаются и восприятия величины, пространства, времени. На занятиях по развитию пространственных отношений затруднения вызывали задания на определение местоположения объекта на листе по инструкции, определение верхней, нижней части листа и особенно правой и левой сторон. Многие дети не пытались исправить свой неверный ответ, некоторые испытуемые отказывались от выполнения задания или бессмысленно указывали на различные объекты, быстро отвлекались. Также на первых занятиях смена учебного кабинета на сенсорную комнату имела расслабляющий дисциплину эффект, тем не менее систематичность занятий, постоянство инструкций и требований, привлекательность рабочего материала скорректировали дисциплину детей. В дальнейшем у детей сформировался устойчивый интерес к занятиям, который сохранялся в течение курса коррекционно-развивающих занятий в 2020/21 учебном году.

Сравнение результатов двух диагностических процедур показало, что количество детей с показателем выше среднего увеличилось с 23 до 28\%, со средним уровнем осталось без изменений - 34\%, с низким уровнем сократилось с 43 до $38 \%$. Статически наблюдается небольшая динамика в развитии сенсомоторных процессов обучающихся.

В результате длительной коррекционной работы у большинства детей сформировались базовые представления о свойствах предметов; умение обследовать предметы с помощью зрительного и тактильного анализаторов; умение устанавливать сходства и различия между однородными предметами; умение группировать предметы по сенсорным признакам. Положительные изменения в сенсорном развитии отметили некоторые родители детей. Например, Обучающийся 1, возраст 12 л., не соотносил и неверно называл цвета, после месяца занятий назвал правильно красный цвет и без ошибок находил в окружающей среде 
С. Д. Будаева. Опыт развития сенсорных процессов обучающихся в условиях коррекционной школы

предметы красного цвета. Обучающийся 2 не соотносил цвета, но у него проявлялась потребность к тактильным мягким ощущениям, поэтому в качестве рабочего материала по освоению цвета были предложены тканевые разноцветные мешочки размером с ладонь и в течение месяца на данном материале мальчик научился соотносить цвета, а затем уже соотносить и группировать другие предметы по цвету [7].

Таким образом, исследование позволило еще раз констатировать, что коррекция недостатков в развитии учащихся с умеренной интеллектуальной недостаточностью происходит медленно и неравномерно, порой трудно заметить небольшие сдвиги в развитии сенсорных процессов, но в то же время данные систематического наблюдения, беседы с родителями и педагогами фиксируют положительные изменения в развитии детей, которые являются результатом целенаправленной коррекционно-развивающей работы.

\section{Литература}

1. Андреева А. А. Потенциал сенсорной комнаты в формировании эталонов цвета, формы, величины у дошкольников с задержкой психического развития // Вестник ТГУ. 2013. Выпуск 12. С. 291. Текст: непосредственный.

2. Большой психологический словарь / под редакцией Б. Г. Мещерякова, акад. В. П. Зинченко. Москва: Прайм-Еврознак, 2003. 672 с. Текст: непосредственный.

3. Будаева С. Д., Монсонова А. Р. Основы специальной педагогики и психологии. Улан-Удэ: Изд-во Бурят. гос. ун-та, 2010. С. 67. Текст: непосредственный.

4. Монтессори М. Дом ребенка. Метод научной педагогики (концепция свободного саморазвития ребенка в специально подготовленной развивающей среде). Москва: Астрель, 2006. 269 с. Текст: непосредственный.

5. Олигофренопсихология // Результаты исследований ощущений и восприятий умственно отсталых детей. 2013. URL: http://www.psi-sintez.org/Psychoparesis/ Rubinstein/VI/12 (дата обращения: 14.05.2020). Текст: электронный.

6. Путинцева С. Ю. Полифункциональная среда сенсорной комнаты как эффективное средство развития зрительного восприятия дошкольников с задержкой психического развития // Новая наука: стратегии и векторы развития. Уфа: Агентство международных исследований, 2016. № 10-1. С. 67. Текст: непосредственный.

7. Рубинштейн С. Я. Психология умственно отсталого школьника // Олигофренопсихология / под редакцией А. С. Синицина. URL: http://www.psisintez.org/Psychoparesis/Rubinstein/VI/12 (дата обращения: 14.05.2020). Текст: электронный.

8. Сенсорное развитие детей младшего дошкольного возраста посредством дидактических игр / Е. С. Козловская, Л. М. Мурашкина, Е. А. Никитенко [и др.] // Молодой ученый. 2017. № 38. С. 112. Текст: непосредственный.

9. Цыренов В. Ц. Проблема социокультурной интеграции детей с ограниченными возможностями здоровья // Вестник БГУ. Серия Педагогика. Улан-Удэ: Изд-во Бурят. гос. ун-та, 2013. № 1. С. 79-85. Текст: непосредственный.

Статья поступила в редакциию 05.06.2021; одобрена после рецензирования 05.07.2021; принята к публикациии 29.11.2021. 


\title{
EXPERIENCE OF PUPILS’ SENSORY DEVELOPMENT IN REMEDIAL SCHOOL ENVIRONMENT
}

\author{
Seseg D. Budayeva \\ Educational Psychologist, \\ Special Secondary Boarding School No. 2 \\ 1 Dalnevostochnaya St., Ulan-Ude 670047, Russia \\ seseg1407@mail.ru
}

\begin{abstract}
The article discusses the importance of sensory development of children with intellectual disabilities. It is noted that visual, sensual acquaintance with objects and their properties is a basis for the harmonious development of the child. Many sensory problems can be overcome only through targeted remedial work. The article analyzes the experience of sensory development of schoolchildren with moderate intellectual disabilities in remedial classes of the boarding school. The intervention program (102 teaching hours) was implemented in the 2020-2021 school year. When assessing sensory indicators, we used the data of N. I. Ozeretsky's and M. O. Gurevich's diagnostic tasks, observations, interviews. Examples of typical situations in remedial classes and the results of the intervention program show that sensory development of children with moderate intellectual disability has some peculiarities.

Keywords: moderate intellectual disability, sensory development, sensory room, results of remedial work, special secondary boarding school.

\section{For citation}

Budayeva S. D. Experience of Pupils' Sensory Development in Remedial School Environment. Education. Person. Society. 2021; 2: 16-20 (In Russ.).
\end{abstract}

The article was submitted 05.06.2021; approved after reviewing 05.07.2021; accepted for publication 29.11.2021. 